\title{
Relationships of active smoking to asthma and asthma severity in the EGEA study
}

\author{
V. Siroux*, I. Pin**, M.P. Oryszczyn*, N. Le Moual*, F. Kauffmann*
}

Relationships of active smoking to asthma and asthma severity in the EGEA study. $V$. Siroux, I. Pin, M.P. Oryszczyn, N. Le Moual, F. Kauffmann. (C)ERS Journals Ltd 2000. ABSTRACT: The role of smoking as potential risk factor, selection factor ("healthy smoker" effect) and modifying factor (severity) of asthma was studied in the Epidemiological study on the Genetics and Environment of Asthma, bronchial hyperresponsiveness and atopy (EGEA).

The analysis involved 200 adult asthmatic cases recruited in chest clinics, 265 nonasthmatic controls and 586 relatives of asthmatics (147 with asthma).

Asthma in childhood was not associated with a reduced take-up of smoking (odds ratio $(\mathrm{OR})=\mathbf{1 . 0 6}$ in males and 0.98 in females), but smoker asthmatic cases quit more often than controls $(\mathrm{OR}=\mathbf{2 . 2 0}(\mathbf{9 5} \%$ confidence interval $(95 \% \mathrm{CI}) \mathbf{1 . 1 1 - 4 . 3 4})$ in males and $2.76(1.19-6.42)$ in females). Adult onset asthma was unrelated to ever smoking (OR 1.07 in males and 1.02 in females). In asthmatic cases, active smoking was associated with asthma severity. Current smokers, compared to never and exsmokers, had more asthma symptoms, more frequent $\left(\geq 1\right.$ attack.day $\left.^{-1}\right)$ asthma attacks (OR 2.39 (95\% CI 1.06-5.36)) and higher asthma severity scores. No clear pattern regarding the relationships of smoking habits with asthma was observed in first degree relatives.

It is concluded that active smoking is not a risk factor for asthma in adulthood, but that smoking increases asthma severity.

Eur Respir J 2000; 15: 470-477.
*Institut National de la Santé et de la Recherche Médicale U472, Villejuif, and **Hôpital Albert Michallon, Grenoble, France.

Correspondence: F. Kauffmann, Epidemiology \& Biostatistics, INSERM U472, 16 avenue PV Couturier, F-94807 Villejuif cedex, France. Fax: 33145595169

Keywords: Asthma, case-control, familial data, severity of asthma, smoking

Received: July 61999

Accepted after revision December 101999

Supported in part by convention Institut National de la Santé et de la Recherche Médicale (INSERM)-Merck Sharp and Dohme, the INSERM networks of clinical research $(489012)$ and public health research (493009), and the Ministry of Environment.
It is generally considered that real asthmatics are nonsmokers [1] and, therefore, relatively little epidemiological research has focused on the relationship of smoking behaviour to asthma. It is recognized that maternal smoking is a risk factor for asthma in children [2] and that smoking increases the incidence of asthma in subjects exposed to some occupational agents [3]. However, there is conflicting evidence as to whether active smoking in general may be a risk factor for asthma, although there are more studies showing no association [4] than studies supporting that hypothesis [5]. The association between smoking and asthma is difficult to understand due to potential biases. Self-selection towards smoking initiation or favouring quitting [6] may mask cross-sectional associations between current smoking and asthma. Such association may also be masked if some smoker asthmatics are labelled with another diagnosis [7]. Studying subjects with some particular susceptibility (occupational exposure or familial history of asthma) may be one means of evidencing the potential role of active smoking in asthma because the relationships may appear stronger in such groups [3, 8]. In asthmatic patients, few studies have analysed the role of smoking as an aggravating factor [9]. A great part of the burden of asthma relates to severe asthma, and smoking may modify the inflammatory characteristics of the disease. Few severe asthmatics are generally included in surveys conducted in general populations, which has limited the study of the effect of smoking on asthma severity.
The general objective was to study the relationship of smoking habits to asthma using the data of the EGEA (Epidemiological study on the Genetics and Environment of Asthma, bronchial hyperresponsiveness and atopy), a case/control study with an examination of first degree relatives of asthmatic cases. The specific objectives were to consider the following complementary aspects: smoking as a potential risk factor for asthma, asthma as a selection factor (healthy smoker effect) and smoking as a modifying factor of asthma (severity).

\section{Methods}

The study combined a case/control study and a family study. The protocol has been described elsewhere [10]. Asthmatic probands were recruited in chest clinics at six clinical centres. The inclusion criteria were place of birth, area of residence, age, familial structure and, for proband cases, a positive answer to the four following standardized questions [10]. Have you ever had attacks of breathlessness at rest with wheezing? Have you ever had asthma attacks? Was this diagnosis confirmed by a physician? Have you had an asthma attack in the last 12 months? Of 446 cases and 1,016 controls who fulfilled all inclusion criteria, 278 cases and 416 controls were examined. A further group of 70 cases who did not answer positively to the four questions but were included after a consensus decision based on their medical records were also 
examined [10]. Adult controls were mostly populationbased (208 were recruited through electoral rolls, 26 through surgery departments and 76 from a check-up centre). The population examined included 348 nuclear families (213 adult and 135 paediatric probands) ascertained through one asthmatic and 416 controls, totalling 1,847 subjects. The study population included for the present analysis comprised 1,071 adults aged $\geq 18$ yrs with data on smoking habits (200 asthmatic cases, 265 nonasthmatic controls, 147 asthmatic relatives of asthmatic cases and 459 nonasthmatic relatives of asthmatic cases). Basic data (including smoking) were recorded through a selfcompleted questionnaire and allowed estimation of whether bias occurred in those who participated to the study. Smoking habits were unrelated to participation. The availability of two questionnaires (self-completed and main questionnaire) allowed the reproducibility (mean delay of 115 days for cases and 83 days for controls) of the smoking habit data to be tested. Two-class (ever and never) and three class (never, exsmoker and current) smoking habit variables exhibit good reproducibility with kappas of 0.90 and 0.88 respectively. The kappas were similar in cases and in controls.

Subjects answered a detailed questionnaire based on the British Medical Research Council (BMRC)/European Coal and Steel Community (ECSC), American Thoracic Society and European Community Respiratory Health Survey (ECRHS) questionnaires [11-13] with additional questions when needed. Smoking was considered in three classes: current smokers, exsmokers and never smokers. Smokers were defined as subjects who reported currently smoking cigarettes, pipes, cigarillos or cigars at the time of the survey. Exsmokers were subjects who had smoked daily and given up $\geq 1$ month before the survey. Nonsmokers were those who had never smoked. The daily consumption of tobacco was evaluated, considering one cigarette, one cigarillo and one cigar equal to 1,2 and $5 \mathrm{~g}$, respectively. Data on tobacco consumption before quitting smoking were collected. Cumulative consumption was computed taking into account current consumption and smoking habits in two preceding periods in cases of change. Heavy cumulative consumption was defined by $\geq 10$ pack-years.

Bronchial challenge and allergy skin-prick testing were performed following mostly the ECRHS protocol. For subjects with a forced expiratory volume in one second (FEV1) of $\geq 80 \%$ of the predicted value, a methacholine bronchial challenge test was performed (maximum dose 4 $\mathrm{mg}$ ) using a Biomedin spirometer (Biomedin Srl, Padua, Italy) in all centres, except in Lyon, where a Pneumotach Jaeger spirometer (Jaeger) was used. The allergens used for the skin-prick tests were all those considered in all areas of the ECRHS survey, i.e. cat, Dermatophagoides pteronyssinus, Cladosporium herbarum, Alternaria tenuis, timothy grass, birch, Parietaria judaica, ragweed, Aspergillus and Blattella germanica were also included in the tests. The prevalence of positive results was a determined using a cutoff of mean weal diameter of $3 \mathrm{~mm}$ greater than that of the negative control.

Asthmatic cases were divided into those with childhood onset asthma (onset 0-15 yrs, 74 cases) and those with adult onset asthma (onset 16-63 yrs, 125 cases). There were no childhood onset asthmatic cases who had started smoking before asthma onset. Among those with adult onset asthma, seven out of the 67 ever smokers started smoking after asthma onset and were excluded from the analysis of smoking as a risk factor for asthma (see below).

A severity score for asthma was established using an a priori decisional tree [14]. Asthmatics were classified as severe if they had more than one asthma attack per week and breathlessness with activity limitation between attacks, severe dyspnoea on exercise or an FEV1 of $<60 \%$ pred, or were hospitalized in the past year for asthma or at least once in the intensive care unit. Mild asthma was defined by less than one attack per week, no persisting symptoms between attacks, no dyspnoea on exercise and an FEV $1 \geq 80 \%$ pred. The remaining asthmatics were classified as moderate. The three classes were coded 1, 2 and 3 for quantitative analysis.

\section{Analysis}

The analysis of the relationship of smoking habits with asthma was conducted following taking a smoking life history. The specific questions addressed were: 1) whether asthma in childhood modifies (decreases) initiation of smoking by comparing ever smoking in childhood onset asthmatics to controls taking into account other potential variables related to the initiation of smoking (i.e. dependent variable is ever smoking); 2) whether smoking (ever) is a risk factor for asthma by comparing adult onset asthmatics to controls regarding ever smoking taking into account other potential variables (such as atopy) related to asthma (i.e. dependent variable is adult onset asthma); 3) whether in ever smokers, asthma (any) modifies smoking behaviour (amount or duration); and 4) whether, in asthmatics, smoking habits modify the characteristics of asthma, in particular its severity.

The statistical analysis included the Chi-squared test for comparison of proportions, the t-test for mean comparisons and logistic regression for multivariate analysis. In ever smokers, a detailed analysis of factors related to quitting smoking was performed using a Cox proportional model. For this, the survival variable was the duration of smoking and the event was quitting. Although no formal matching was performed in the design phase for age, sex, and city, there was an attempt to balance cases and controls regarding these characteristics. Therefore, it was checked in all analyses that adjustment for these three variables did not change conclusions, but results are not always presented with adjustment for city due to the small numbers involved. The statistical software package SAS (SAS Institute, Cary, NC, USA) was used.

\section{Results}

Demographic characteristics, atopy and lung function are presented in table 1 for cases and controls, and for the first degree relatives of asthmatics according to their personal history of asthma. The mean age of onset was 6.5 yrs for cases with childhood onset and 33.4 yrs for cases with adult onset asthma. Regarding sociodemographic characteristics, cases and controls were similar except for a somewhat lower proportion of professionals among female cases than among female controls (14.6 versus $28.1 \% ; \mathrm{p}=0.09$ ). 
Table 1. - Study population

\begin{tabular}{|c|c|c|c|c|}
\hline & \multirow[t]{2}{*}{$\begin{array}{l}\text { Asthmatic } \\
\text { cases }\end{array}$} & \multirow{2}{*}{$\begin{array}{l}\text { Non- } \\
\text { asthmatic } \\
\text { cases }\end{array}$} & \multicolumn{2}{|c|}{$\begin{array}{l}\text { First degree relatives } \\
\text { of asthmatics }\end{array}$} \\
\hline & & & Asthmatics $^{+}$ & $\begin{array}{c}\text { Non- } \\
\text { asthmatics }\end{array}$ \\
\hline Subjects $n$ & 200 & 265 & 147 & 459 \\
\hline Sex \% male & 52.0 & 48.3 & 49.7 & 47.3 \\
\hline Age yrs & $40.1 \pm 13.6$ & $42.0 \pm 12.7$ & $36.5 \pm 11.4$ & $38.8 \pm 11.5$ \\
\hline Atopy* \% & 67.2 & 30.7 & 75.7 & 37.6 \\
\hline FEV1 \% pred & $87.1 \pm 21.1$ & $105.0 \pm 14.2$ & $100.6 \pm 18.1$ & $105.5 \pm 13.5$ \\
\hline $\begin{array}{l}\text { Methacholine } \\
\text { challenge n } \\
\text { PD20 }\end{array}$ & 70 & 193 & 99 & 376 \\
\hline$\leq 4 \mathrm{mg} \%$ & 87.1 & 24.9 & 63.6 & 29.3 \\
\hline
\end{tabular}

Data are presented as mean $\pm \mathrm{SD}$ for age and forced expiratory volume in one second (FEV1), *: weal $\geq 3 \mathrm{~mm}$ greater diameter than control; ${ }^{+}: 91$ parents, 30 siblings and 26 offspring of asthmatic probands; : 307 parents, 62 siblings and 90 offspring of asthmatic probands. The inclusion criteria for asthmatic cases were based on four standardized questions [10]. In relatives, asthma was defined by a positive answer to one of two questions (Q): Q21 (attack of breathlessness with wheezing) and/or Q22 (asthma attack ever). PD20: provocative dose of methacholine causing a $20 \%$ fall in FEV1.

\section{Initiation of smoking}

Eversmoking was as common in asthmatic cases as in controls (table 2), for males (63.5 versus $61.7 \%$, odds ratio $(\mathrm{OR})=1.08,95 \%$ confidence interval $(\mathrm{CI})(0.63-$ $1.84)$ ) and females (41.7 versus $39.4 \%$, OR $1.10,95 \% \mathrm{CI}$ $0.65-1.87)$. Male cases started smoking 1 yr younger than controls (table 2). Whether childhood onset asthma (38 males and 36 females) might modify initiation of smoking was studied. There was no relation between childhood onset asthma and ever smoking in both males (OR 1.06, 95\% CI $0.50-2.25$ ) and in females (OR $0.98,95 \%$ CI 0.46-2.08). Model 1 in table 3 shows that, after adjustment for age, city and socio-occupational class, the ad-
Table 3. - Relationship of asthma to active smoking: study of cases and controls

\begin{tabular}{|c|c|c|}
\hline & Males & Females \\
\hline \multicolumn{3}{|c|}{ Childhood asthma as potential selection } \\
\hline Ever smoking* $\mathrm{n}$ & 164 & 171 \\
\hline Childhood onset & $185(077-444)$ & $097(0.41-2.28)$ \\
\hline Age (for $10 \mathrm{yrs}$ ) & $1.18(0.87-1.59)$ & $0.72(0.52-0.99)$ \\
\hline \multicolumn{3}{|c|}{ Tobacco smoking as potential risk factor for asthma } \\
\hline Adult onset asthma* n & 184 & 187 \\
\hline $\begin{array}{l}\text { Ever smoking } \\
\text { (ves yersus no) }\end{array}$ & $121(0.55-267)$ & $1.19(0,60-2.36)$ \\
\hline Age $(10 \mathrm{yrs})^{\#}$ & $1.73(1.25-2.38)$ & $1.16(0.87-1.54)$ \\
\hline Atopy+(yes versus no) & $8.63(3.60-20.70)$ & $2.09(1.03-4.23)$ \\
\hline
\end{tabular}

Data are presented as an odds ratio (95\% confidence interval). *: dependent variable; ${ }^{+}$: weal $\geq 3 \mathrm{~mm}$ greater diameter than control; \#: computed for a $10-\mathrm{yr}$ difference from the logistic regression in which age was entered as a quantitative variable. The selection factor logistic regression model includes childhood onset asthma, age (yrs), socio-occupational class and city. The risk factor logistic regression model includes ever smoking, age (yrs), atopy and city. Asthmatics with asthma and onset before starting smoking $(n=7)$ were excluded.

justed ORs increased in males and was unchanged in females, but in both cases remain nonsignificant.

\section{Smoking as a risk factor for asthma}

Whether smoking is a risk factor for asthma was studied by restricting the comparison of controls to asthmatics to those with adult onset after smoking initiation (table 3). Ever smokers were at a similar risk of adult onset asthma to never smokers (OR 1.07 (95\% CI 0.54-1.87) in males and $1.02(0.54-1.94)$ in females. Adjustment for age, atopy and city, increased the association slightly for both males and females but remained nonsignificant. In adult onset cases, smoking was unrelated to the age at asthma onset. Reconstructing the amount of tobacco smoked before 20 yrs of age, there was no difference between

Table 2. - Smoking habits in cases and controls by sex

\begin{tabular}{|c|c|c|c|c|c|c|}
\hline & \multicolumn{3}{|c|}{ Male } & \multicolumn{3}{|c|}{ Female } \\
\hline & $\begin{array}{c}\text { Asthmatic } \\
\text { cases }\end{array}$ & $\begin{array}{l}\text { Nonasthmatic } \\
\text { controls }\end{array}$ & p-value & $\begin{array}{c}\text { Asthmatic } \\
\text { cases }\end{array}$ & $\begin{array}{c}\text { Nonasthmatic } \\
\text { cases }\end{array}$ & p-value \\
\hline Subjects $n$ & 104 & 128 & & 96 & 137 & \\
\hline Age yrs & $42.2 \pm 14.1$ & $43.4 \pm 13.2$ & $>0.10$ & $37.5 \pm 12.7$ & $40.6 \pm 12.1$ & 0.06 \\
\hline Never smokers $\%$ & 36.5 & 38.3 ) & & 58.3 & $60.6)$ & \\
\hline Exsmokers \% & 43.3 & $30.5\}$ & 0.07 & 25.0 & $13.9\}$ & 0.05 \\
\hline Current smokers $\%$ & 20.2 & 31.2 J & & 16.7 & 25.5 J & \\
\hline Ever smokers $n$ & 66 & 79 & & 40 & 54 & \\
\hline Age yrs & $42.6 \pm 12.8$ & $45.7 \pm 12.3$ & - & $37.7 \pm 12.0$ & $39.0 \pm 10.7$ & - \\
\hline Age at start of smoking yrs & $16.8 \pm 2.2$ & $17.9 \pm 3.8$ & 0.04 & $18.6 \pm 5.1$ & $19.0 \pm 10.7$ & - \\
\hline Cumulative tobacco consumption pack-yrs & $13.5 \pm 11.4$ & $15.9 \pm 14.3$ & - & $6.9 \pm 10.2$ & $9.9 \pm 11.0$ & - \\
\hline Current smokers $\mathrm{n}$ & 21 & 40 & & 16 & 35 & \\
\hline Age yrs & $36.0 \pm 12.6$ & $40.5 \pm 11.8$ & - & $33.2 \pm 11.5$ & $36.2 \pm 11.3$ & - \\
\hline Daily tobacco consumption $\mathrm{g} \cdot \mathrm{day}^{-1}$ & $11.1 \pm 7.6$ & $15.4 \pm 2.2$ & 0.10 & $8.4 \pm 4.0$ & $10.6 \pm 8.1$ & - \\
\hline Exsmokers $n$ & 45 & 39 & & 24 & 19 & \\
\hline Age yrs & $45.6 \pm 11.9$ & $50.9 \pm 10.5$ & 0.03 & $40.7 \pm 11.7$ & $44.2 \pm 7.2$ & - \\
\hline Daily tobacco consumption before quitting $\mathrm{g} \cdot \mathrm{day}^{-1}$ & $17.6 \pm 12.4$ & $17.1 \pm 11.9$ & - & $9.8 \pm 6.6$ & $13.3 \pm 13.1$ & - \\
\hline Age at start of smoking yrs & $17.1 \pm 2.0$ & $18.5 \pm 3.7$ & 0.03 & $19.2 \pm 6.2$ & $20.4 \pm 7.9$ & - \\
\hline Age at quitting smoking yrs & $33.9 \pm 9.7$ & $38.3 \pm 10.2$ & 0.05 & $29.3 \pm 9.1$ & $32.1 \pm 9.4$ & - \\
\hline
\end{tabular}

Data are presented as mean $\pm \mathrm{SD}$, absolute values or percentages. 

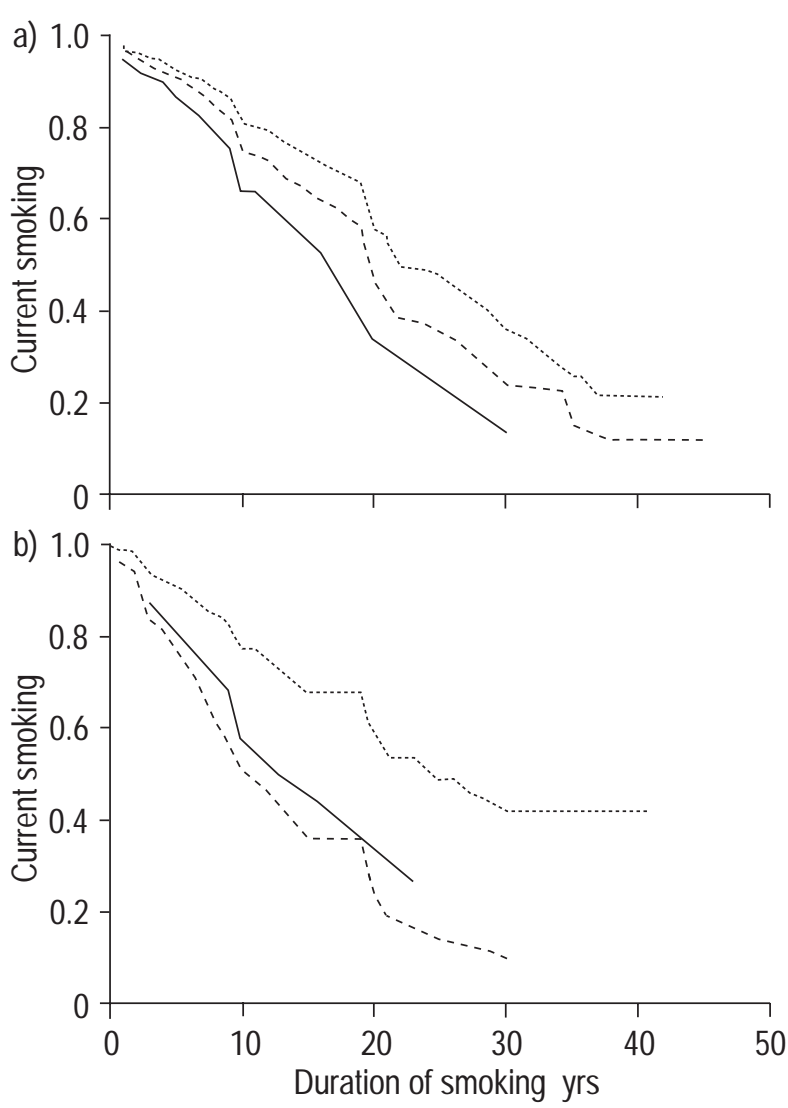

Fig. 1. - Estimation of smoking duration using a Cox model among asthmatic cases ( - : childhood onset; - - - - : adult onset) and nonasthmatic controls (….....) by sex. a) male; and b) female. Considering all asthmatics together versus controls (male: $n=74$; female: $n=47$ ) gave a relative risk (RR) of 1.50 (95\% confidence interval (CI) $0.97-2.34$ ) in males and 2.48 (95\% CI 1.32-4.66) in females. Splitting cases into those with childhood and adult onset gave a RR compared to nonasthmatic controls in adulthood of $1.38(95 \%$ CI $0.85-2.23$; $\mathrm{n}=40)$ and in childhood of $1.96(95 \%$ CI $1.01-3.80 ; n=22)$ in males and in adulthood of $2.66(95 \%$ CI $1.35-5.23 ; n=26)$ and in childhood of 2.13 (95\% CI $0.87-$ $5.21 ; \mathrm{n}=14)$ in females.

controls of $\geq 20$ yrs and asthmatics with an age at onset of $\geq 20 \mathrm{yrs}$. This suggests that the quantity of tobacco smoked during adolescence is not a risk factor for adult onset asthma. Environmental tobacco smoke as a trigger of asthma attacks was reported at the time of interview significantly more in never smoker than in exsmoker and current smoker asthmatics $(68.9,48.5$ and $38.9 \%$ respectively, $\mathrm{p}=0.003$ ).

\section{Amount and duration of smoking}

In contrast to ever smoking, exsmoking was significantly related to asthma for both males (OR 2.20, 95\% CI 1.11-4.34) and females (OR 2.76, 95\% CI 1.19-6.42), with no significant difference between sexes. Among exsmokers, both male (OR 3.88, 95\% CI 1.44-10.45) and female (OR 3.21, 95\% CI 0.81-12.75) asthmatics more often reported that they stopped because of their bronchi. The pattern of quitting smoking was studied in the population. Overall, the age at quitting was nearly 5 yrs younger in cases than in controls (table 2). The detailed analysis of smoking duration in cases and controls using Cox models (fig. 1) further demonstrated that cases stopped smoking earlier than controls in males and in females $(\mathrm{p}=$ 0.07 and $p=0.005$, respectively). Comparison of smoking duration in cases with childhood and adult onset of asthma and in controls showed that men with childhood onset stopped earlier than those with adult onset, who themselves stopped earlier than controls. Males with childhood onset stopped significantly earlier than controls $(p=0.05)$. No difference according to age of onset was observed in females. Adjustment of the Cox models for level of education, socio-occupational class and atopy did not modify the relationships. The amount of tobacco consumed by asthmatics and controls was equal or slightly lower in asthmatics in the last (current or prior to stopping) period of smoking history, but this difference was only of borderline significance for current smokers in males (table 2).

\section{Smoking as a modifying factor}

The modifying effect of smoking habits on the clinical and functional manifestations of asthma was studied (table 4). Current smokers more often reported a frequency of asthma attacks of $\geq 1$ attack $\cdot$ day $^{-1}$ than did others, with an OR of 2.39 (95\% CI 1.06-5.36). Current smokers more often reported an attack of breathlessness in the last 12 months and abnormal breathing between attacks than others, with ORs of 5.39 (95\% CI 1.82-15.84) and 2.06 (95\% CI 0.97-4.36) respectively. Asthmatics with a high cumulative consumption reported a higher proportion of abnormal breathing compared to other asthmatics, with an OR of 2.14 (95\% CI 1.05-4.36).

Using the severity score (see methods), 23 asthmatics were classified as mild, 96 as moderate and 81 as severe. The percentages of current smokers were 13, 12.5 and $27.2 \%$ in asthmatics with mild, moderate and severe asthma respectively (current smokers versus others $\mathrm{p}=0.03$; $\mathrm{p}$-value for trend $\mathrm{p}=0.02$ ). In male never smokers, exsmokers and current smokers, the scores were 2.13, 2.24 and 2.43 and in female $2.30,2.25$ and 2.62 respectively. As shown in table 4 , after adjustment for age and sex, the relation of smoking to severity score was statistically significant $(\mathrm{p}=0.02)$. A lower educational level significantly related to a higher severity score $(2.52,2.20$ and 2.19 for primary, secondary and university level, $\mathrm{p}=0.01$ ). The strength of the relation of severity score with smoking increased slightly after adjustment for educational level $(p=0.01)$. As for the separate severity items, exsmokers exhibited severity scores similar to never smokers. The asthmatics with a history of a high cumulative consumption had higher scores, but the relation was nonsignificant (the age and sex-adjusted scores were 2.22, 2.28 and 2.47 for never smokers and smokers with cumulative consumptions of $<10$ pack-yrs and $\geq 10$ packyrs respectively).

Exsmokers were similar to never smokers for all the items considered and the severity score. Comparison of exsmokers to current smokers showed that on average exsmokers had less severe asthma than current smokers for most characteristics. A borderline significant difference was observed for a frequency of attacks of $\geq 1$ attack $\cdot$ day $^{-1}$, with an OR in current smokers versus exsmokers of 2.43 (95\% CI 0.96-6.21). The severity score in current smokers 
Table 4. - Severity of asthma according to smoking in asthmatic cases

\begin{tabular}{|c|c|c|c|c|}
\hline & Never smokers & Exsmokers & Current smokers & p-value \\
\hline Subjects $n$ & 94 & 69 & 37 & \\
\hline Sex $\%$ male & 40.4 & 65.2 & 56.8 & 0.006 \\
\hline Age yrs & $39.4 \pm 14.7$ & $43.9 \pm 11.9$ & $34.8 \pm 12.1$ & 0.003 \\
\hline Age at onset yrs & $22.0 \pm 15.0$ & $26.7 \pm 17.5$ & $18.6 \pm 14.8$ & 0.03 \\
\hline Attacks of breathlessness at rest in the last 12 months \% & 60.6 & 60.3 & 89.2 & 0.004 \\
\hline Asthma attacks frequency $\geq 1 \cdot$ day $^{-1} \%$ & 18.2 & 17.6 & 34.3 & 0.10 \\
\hline Normal breathing between attacks \% & 78.9 & 68.1 & 58.3 & 0.05 \\
\hline Woken by chest tightness in the last 12 months \% & 84.0 & 87.0 & 86.5 & 0.86 \\
\hline Woken by attack of shortness of breath in the last 12 months \% & 65.6 & 68.7 & 73.0 & 0.71 \\
\hline Woken by attack of coughing in the last 12 months $\%$ & 51.0 & 59.7 & 64.9 & 0.29 \\
\hline FEV1 \% pred & $86.0 \pm 20.9$ & $85.6 \pm 21.5$ & $92.9 \pm 20.4$ & 0.19 \\
\hline \multicolumn{5}{|l|}{ Methacholine challenge test } \\
\hline Subjects $n$ & 34 & 18 & 18 & \\
\hline PD20 $\leq 4 \mathrm{mg} \%$ & 82.3 & 88.9 & 94.4 & 0.45 \\
\hline Severity score & $2.23 \pm 0.64$ & $2.25 \pm 0.67$ & $2.51 \pm 0.65$ & 0.07 \\
\hline Age and sex-adjusted & 2.22 & 2.23 & 2.57 & 0.02 \\
\hline Age, sex and educational level adjusted & 2.21 & 2.23 & 2.66 & 0.01 \\
\hline
\end{tabular}

Data are presented as mean $\pm \mathrm{SD}$, absolute value or percentages. FEV1: forced expiratory volume in one second. PD20: provocative dose of methacholine causing a 20\% fall in FEV1.

was significantly higher than that in exsmokers (unadjusted score $p=0.05$; age, sex and educational level adjusted $\mathrm{p}=0.008$ ).

Further analysis of the relationship of smoking habits to severity was conducted using an indirect longitudinal approach. The change in frequency of asthma attacks in relation to smoking was studied indirectly by considering the 74 subjects with childhood onset for whom data on the frequency of attacks was recorded both in childhood (before any smoking) and at the time of examination. There was an increase in the frequency for $30 \%$ of the subjects, an unchanged frequency for $39 \%$, and a decreased frequency for $31 \%$. A high cumulative tobacco consumption ( $\geq 10$ pack-yrs) showed some relationship with the increase from the childhood to the adulthood frequency of asthma attacks (child/adult increase), but the association did not reach significance. Compared to never smokers $(n=30)$, the ORs for the child/adult increase in asthma attacks were, for heavy $(n=11)$ and moderate $(n=20)$ consumption, 3.94 (95\% CI 0.92-16.94) and 1.09 (95\% CI 0.29-4.10) respectively. After adjustment for age and sex, the results were similar.

\section{Smoking habits in first degree relatives of asthmatics}

The association between smoking habits and asthma was analysed in the first degree relatives of asthmatic probands. The smoking status in asthmatic relatives and in nonasthmatic relatives are compared in table 5. As in the comparison between cases and controls, asthma was unrelated to ever smoking in first degree relatives. Ageadjusted ORs for asthma in relation to ever smoking were 0.84 (95\% CI $0.48-1.47)$ for males and 0.98 (95\% CI $0.58-1.66)$ for females.

The pattern of relation of smoking habits to quitting smoking and severity of asthma was less clear than among cases and controls. Neither in the whole group of first degree relatives, nor in any subgroup (fathers, mothers, sons, daughters, brothers and sisters) was the relation statistically significant. In order to assess the potential influence of asthma in offspring on parental smoking habits, a graphical analysis (not shown) of the respective timing of parental quitting of smoking to offspring asthma onset was performed. The number of subjects was limited, but no particular pattern emerged. Asthmatic relatives were less severe than asthmatic cases considering the various indices and the composite severity score $(1.79 \pm .59$ versus $2.29 \pm$ 0.66 respectively). In asthmatic first degree relatives, there was no significant association of severity criteria with smoking habits, even considering a high cumulative tobacco consumption.

\section{Discussion}

Comparison of asthmatic cases (recruited in chest clinics) and nonasthmatic controls from the EGEA study showed that asthma was not associated with a decrease in taking up smoking, but that smoker cases stopped smoking earlier than controls. Analyses of the asthmatic cases showed that active smoking was associated with an increase in asthma severity. Current smokers compared to never and exsmokers had more asthma symptoms, more frequent asthma attacks and a higher asthma severity score. The study of first degree relatives of asthmatic probands did not show a clear pattern regarding the relationships of smoking habits with asthma.

Asthmatic cases recruited in chest clinics were ascertained through standardized methods [10]. Asthmatic probands to be included either positively answered four standardized questions or fulfilled the criteria for a positive consensus evaluation for those who positively answered two or three questions. A previous analysis showed that the consensus evaluation had good reproducibility [10]. The unclear pattern observed in the comparison of asthmatics and nonasthmatic first degree relatives may relate to the less restrictive definition of asthma based only on two questions from the BMRC/ECSC questionnaire, and they did have less severe asthma.

One limitations of the present study is the cross-sectional nature of the data. In an attempt to understand the chronological relationship between asthma onset and smoking behaviour, some longitudinal information gathered retrospectively was analysed [12]. It was not possible to study 
Table 5. - Smoking habits among first degree relatives of asthmatic probands according to their asthma status

\begin{tabular}{|c|c|c|}
\hline & Asthmatics & Nonasthmatics \\
\hline \multicolumn{3}{|l|}{ Fathers } \\
\hline Subjects $n$ & 45 & 153 \\
\hline Age yrs & $43.9 \pm 7.4$ & $46.1 \pm 7.7^{+}$ \\
\hline Never smokers \% & 32.6 & 25.5 \\
\hline Exsmokers \% & 43.5 & 38.6 \\
\hline Current smokers \% & 233.9 & 35.9 \\
\hline \multicolumn{3}{|l|}{ Mothers } \\
\hline Subjects $n$ & 45 & 154 \\
\hline Age yrs & $43.4 \pm 7.7$ & $44.7 \pm 7.2$ \\
\hline Never smokers \% & 60.0 & 59.1 \\
\hline Exsmokers \% & 24.4 & 23.4 \\
\hline Current smokers \% & 15.6 & 17.5 \\
\hline \multicolumn{3}{|l|}{ Brothers } \\
\hline Subjects $n$ & 16 & 24 \\
\hline Age yrs & $23.7 \pm 5.6$ & $24.3 \pm 6.6$ \\
\hline Never smokers \% & 75.0 & 75.0 \\
\hline Exsmokers \% & 0.0 & 4.2 \\
\hline Current smokers \% & 25.0 & 20.8 \\
\hline \multicolumn{3}{|l|}{ Sisters } \\
\hline Subjects $n$ & 14 & 38 \\
\hline Age yrs & $26.1 \pm 6.7$ & $25.8 \pm 5.7$ \\
\hline Never smokers \% & 50.0 & 52.6 \\
\hline Exsmokers \% & 7.1 & 13.2 \\
\hline Current smokers \% & 42.9 & 34.2 \\
\hline \multicolumn{3}{|l|}{ Sons } \\
\hline Subjects $n$ & 11 & 40 \\
\hline Age yrs & $25.2 \pm 3.0$ & $26.2 \pm 5.4$ \\
\hline Never smokers \% & 36.4 & 47.5 \\
\hline Exsmokers \% & 18.2 & 12.5 \\
\hline Current smokers \% & 45.4 & 40.0 \\
\hline \multicolumn{3}{|l|}{ Daughters } \\
\hline Subjects $n$ & 15 & 50 \\
\hline Age yrs & $24.5 \pm 4.6$ & $26.2 \pm 5.3$ \\
\hline Never smokers \% & 46.7 & 48.0 \\
\hline Exsmokers \% & 6.7 & 20.0 \\
\hline Current smokers \% & 46.6 & 32.0 \\
\hline
\end{tabular}

Data are presented as mean $\pm \mathrm{SD}$, absolute values or percentages. The inclusion criteria for asthmatic cases were based on four standardized questions [10]. In relatives, asthma was defined by a positive answer to one or two questions (Q): Q21 (attack of breathlessness with wheezing) and/or Q22 (asthma attack ever). ${ }^{+}: \mathrm{p}<0.10$.

asthmatics with childhood onset without symptoms in adulthood as current asthma was one of the inclusion criteria.

In the present study, smoking was not a risk factor for asthma. It was analysed considering cross-sectional data at the time of the examination, but also considering adulthood asthma in relation to previous smoking. The epidemiological analysis of the associations of smoking with asthma has been the focus of relatively few epidemiological studies. The lack of association observed in the EGEA is consistent with other reports, based on large representative population samples [4, 16-19]. Longitudinal data from the Nurses Health Study showed that asthma incidence was significantly lower in current smokers than in never smokers [19]. This reverse association was interpreted as self-selection of female continuous smokers who could be a subgroup of females less susceptible to asthma.

The results of several studies conducted in Scandinavia support the hypothesis that smoking may be a risk factor for asthma [5, 20-22]. However, a 6-yr longitudinal study did not confirm the association observed cross-sectionally in a Finnish cohort [22]. Another longitudinal study showed that the incidence of asthma over a follow-up period of 3.5 yrs was significantly greater in current smokers com-pared to other subjects [7]. However, the association was significant only in subjects aged $<40$ yrs at the beginning of the study. The definitions of asthma used varied between studies, which could partly explain differences in results. For now, there is limited evidence that smoking is a risk factor for asthma, but this remains puzzling as tobacco consumption is an established risk factor for intermediate phenotypes of asthma, such as elevated immunoglobulin E levels [23] and bronchial hyperresponsiveness [24] and maternal smoking relates to childhood asthma [2].

The lack of association of current smoking with asthma may relate to selection factors, either that asthmatics start to smoke less often or that they are more prone to quit. In the population studied, the presence of asthma did not deter subjects from starting smoking, even when considering only childhood onset asthmatics. These results are consistent with other reports of studies conducted in adolescents in the UK [25] and in the first US National Health and Nutrition Examination Survey [16], which have shown that adolescent asthmatics started smoking as often as nonasthmatics.

In the EGEA, twice as many asthmatic cases as controls were exsmokers. A detailed analysis of smoking duration in eversmokers using a Cox model showed that the pattern of quitting smoking different according to sex and the age of onset. Asthmatic females quitted more often than asthmatic males. Among males, those with childhood onset asthma quitted smoking earlier than those with adult onset. Among females, the pattern of quitting smoking in asthmatics was similar in those with childhood and adult onset asthma.

In a case/control study in Sweden on 79 cases and 304 controls, asthma was significantly related to exsmoking with an OR of $\sim 3$ [5]. Cross-sectional data from the large cohort study in Finland [22] showed some nonsignificant association of asthma with exsmoking in males (OR 1.69), but none in females (OR 1.05). Quitting smoking during a 6-yr follow-up period was only slightly more common among subjects who reported asthma at the beginning than in others (OR 1.23, ns). Longitudinal observations from the Nurses Health Study [19] showed that asthma incidence was higher in recent quitters than in never smokers, but there was no difference in asthma incidence between never smokers and those who had quitted $\geq 5$ yrs ago. The authors concluded that their observations were compatible with the hypothesis that smoking is a risk factor for asthma as asthma-like symptoms could induce quitting smoking, but, when quitting occurs too late, asthma-like symptoms then became a predictor of a doctor's diagnosis of asthma.

First degree relatives a priori represented an appropriate population in which to assess whether active smoking was a risk factor for asthma, as such subjects are a priori more susceptible to environmental agents than the general population. Indeed, in a Norwegian study [8] conducted in a large population of farmers, the OR of current smoking with asthma was markedly higher in those with a family history of asthma than in those without $(8.5$ (95\% CI 3.7-20.2) versus 1.9 (95\% CI 0.9-3.8)). No association of smoking with asthma was observed in the 
population of relatives in the EGEA. The lack of relation of asthma to exsmoking in relatives, although it was observed in the case/control component of the EGEA and although weaker in several general populations [4, 22], supports the hypothesis that the pattern of smoking in families with asthmatics is complex. In the general population, it is well known that there is assortative marriage for smoking habits and that smoking habits in offspring are strongly influenced by parental smoking, but there is limited information on smoking habits in families with asthma.

In the asthmatic cases, clinical and functional manifestations of asthma were significantly related to smoking. Smokers reported attacks of breathlessness, a high frequency of asthma attacks and abnormal breathing between attacks significantly more often. A severity score established for the study [14] was significantly higher among smokers compared to never smokers. The cross-sectional results on the association of current smoking with asthma severity were supported by longitudinal retrospective information. Analysis of the child/adult change showed that the increase in asthma attack frequency was greater in heavy smokers than in moderate smokers. Overall, the results were consistent across the various analyses conducted (individual items, composite score, cross sectional data and retrospective longitudinal approach).

The results obtained in the case/control EGEA extend previous epidemiological and clinical observations on the relationship of smoking to asthma severity. Death caused by asthma in 1000 outpatient asthmatics followed over 20 yrs was significantly related to cumulative tobacco consumption [26], but smoking habits did not predict death in a large sample of asthmatics [27]. Three clinical reports concern the relation of near-fatal asthma to smoking. One US study reported that exposure to smoking (active or passive) was associated (OR $~ 7)$ with near-fatal asthma [28], an association consistent with the OR of $>4$ observed in Canada for the association of current smoking to hospitalization in an emergency department [29] but not supported by observations from another Canadian report on near-fatal asthma [30]. The 6-yr survival in those recovering from near-fatal asthma was related to active smoking [31], with an age-adjusted OR of 3.6. A borderline significant association was observed, in a large clinical study from Singapore, with current smoking when moderate/severe asthma (defined by frequency of attacks, general practitioner consultations and/or hospitalizations) was compared to mild cases [32]. Smoking was also shown to increase hospitalizations for asthma [33]. In a longitudinal study, conducted in the general population of Copenhagen, in which the 15-yr FEV1 slope was at least twice as steep in asthmatics as in nonasthmatics in both males and females, smoking further significantly accelerated the relative decline in lung function in both asthmatic and nonasthmatic adults [21]. Results in adults from the EGEA are consistent with findings in children, for whom there is good evidence that parental smoking influences asthma severity in children [2]. Significant associations of parental smoking with asthma severity in children have been observed considering various severity dimensions, such as the frequency of wheezing episodes, the persistence of symptoms between attacks, life-threatening events or composite severity scores [2].
Associations of environmental risk factors, such as smoking or air pollution [2], with asthmatic symptoms, lung function, composite severity scores or even fatal or near-fatal attacks could reflect an acute effect of these factors, inducing exacerbations of the disease rather than an increase in the underlying severity. Few studies have differentiated between acute and chronic effects [26]. Whatever the effects on exacerbations or underlying severity, such associations are of clinical importance.

The similar values in never and exsmokers observed in the EGEA for severity indices support the hypothesis that the effect of smoking on asthma severity may be reversible, which is coherent with longitudinal observations in children with asthma whose parents smoking decreased [34].

Results from the Epidemiological Study on the Genetics and Environment of Asthma, bronchial hyperresponsiveness and atopy show that a personal and familial history of asthma modify smoking habits, but that the pattern is rather complex due to regulation factors. Longitudinal data are needed in order to better understand the temporal relationship of smoking initiation and quitting to asthma symptomatology. Greater attention should be paid to smoking in asthmatics as a high proportion of asthmatics followed in chest clinics are still current smokers, as previously noted $[31,35]$. If smoking is not a risk factor for asthma, it plays a role in the severity and lack of control of asthma. More attention should be paid to antismoking campaigns in asthmatics, particularly among asthmatic adolescents, to deter them from starting smoking.

EGEA co-operative group: Respiratory epidemiology: I. Annesi-Maesano, F. Kauffmann (co-ordinator), M.P. Oryszczyn (Institut National de al Santé et de la Recherche Médicale (INSERM) U472, Villejuif); F. Neukirch, M. Korobaeff (INSERM U408, Paris). Genetics: M.H. Dizier, J. Feingold (INSERM U155, Paris), F. Demenais (INSERM U358, Paris), M. Lathrop (INSERM U358, then Wellcome Trust Centre of Human Genetics, Oxford, now at the Centre National de Génotypage, Evry). Clinical centres: Grenoble: I. Pin, C. Pison; Lyon: D. Ecochard ${ }^{\dagger}$, F. Gormand, Y. Pacheco; Marseille: D. Charpin, D. Vervloet; Montpellier: J. Bousquet; Paris Cochin: A. Lockhart, R. Matran (now in Lille); Paris Necker: E. Paty, P. Scheinmann; ParisTrousseau: A. Grimfeld. Data management: J. Hochez (INSERM U 155), N. Le Moual (INSERM U472).

Acknowledgements: The authors thank all those who participated in the design phase of the study, or who worked at its co-ordination throughout the years, the interviewers from the various centres and the subjects and their families who participated in the study.

\section{References}

1. Panhuysen CI, Bleecker ER, Koeter GH, Meyers DA, Postma DS. Characterization of obstructive airway disease in family members of probands with asthma. An algorithm for the diagnosis of asthma. Am J Respir Crit Care Med 1998; 157: 1734-1742.

2. Strachan DP, Cook DG. Parental smoking and childhood asthma: longitudinal and case-control studies. Thorax 1998; 53: 204-212.

3. Venables KM, Upton JL, Hawkins ER, Tee RD, Longbottom JL, Newman Taylor AJ. Smoking, atopy, and laboratory animal allergy. Br J Ind Med 1988; 45: 667-671. 
4. Higgins MW, Keller JB, Metzner HL. Smoking, socioeconomic status and chronic respiratory disease. Am Rev Respir Dis 1977; 116: 403-410.

5. Flodin U, Jönsson P, Ziegler J, Axelson O. An epidemiology study of bronchial asthma and smoking. Epidemiology 1995; 6: 503-505.

6. Becklake MR, Lalloo U. The "healthy smoker": a phenomenon of health selection? Respiration 1990; 57: 137144.

7. Dodge RR, Burrows B. The prevalence and incidence of asthma and asthma-like symptoms in a general population sample. Am Rev Respir Dis 1980; 122: 567-575.

8. Melbostad E, Eduard W, Magnus P. Determinants of asthma in a farming population. Scand $J$ Work Environ Health 1998; 24: 262-269.

9. Strunk RC, Nicklas RA, Milgrom H, Davis ML, Iklé DN. Risk factors for fatal asthma. In: Sheffer AL, Ed. Fatal asthma. Basle, Marcel Dekker, 1998; pp. 31-44.

10. Kauffmann F, Dizier MH, Pin I, et al. Epidemiological study of the genetics and environment of asthma, bronchial hyperresponsiveness and atopy (EGEA) -phenotype issues. Am J Respir Crit Care Med 1997; 156: S123S129.

11. Brille D, Casula D, van der Lende R, Smidt U. Commentaires relatifs au questionnaire pour l'étude de la bronchite chronique et de l'emphysème pulmonaire (1967). Collection d'hygiènect de médecine du travail. No. 14. Luxembourg CEE-CECA, 1971.

12. Ferris BG. Epidemiology standardization project. Am Rev Respir Dis 1978; 118: 7-53.

13. Anonymous. United Medical and Dental schools of Guy's and St-Thomas's Hospitals, Department of Public Health Medicine. Protocol for the European Community Respiratory Health Survey. London, 1993;

14. Pin I, Cans C, Gousset M, Gormand F, Pison C. Respiratory symptoms in mild and severe asthmatic adults in EGEA (Epidemiological Study on the Genetics and Environment of Asthma). Eur Respir J 1997; 10: Suppl 25, 144s.

15. Kauffmann F, Maccario J. Cross-sectional analyses of longitudinal data and longitudinal analyses of crosssectional data. Eur Respir Rev 2000 (in press).

16. McWhorter WP, Polis MA, Kaslow RA. Occurrence, predictors, and consequences of adult asthma in NHANES I and follow-up survey. Am Rev Respir Dis 1989; 139: 721-724.

17. Wakefield M, Ruffin R, Campbell D, Roberts L, Wilson D. Smoking-related beliefs and behaviour among adults with asthma in a representative population sample. Aust $N$ Z J Med 1995; 25: 12-17.

18. Lebowitz MD. Smoking habits and changes in smoking habits as they relate to chronic conditions and respiratory symptoms. Am J Epidemiol 1977; 105: 534-543.

19. Troisi RJ, Speizer FE, Rosner B, Trichopoulos D, Willett WC. Cigarette smoking and incidence of chronic bronchitis and asthma in women. Chest 1995; 108: 1557-1561.
20. Larsson L. Incidence of asthma in Swedish teenagers: relation to sex and smoking habits. Thorax 1994; 50: 260-264.

21. Lange P, Parner J, Vestbo J, Schnohr P, Jensen G. A 15year follow-up study of ventilatory function in adults with asthma. N Engl J Med 1998; 339: 1194-1200.

22. Vesterinen E, Kaprio J, Koskenvuo M. Prospective study of asthma in relation to smoking habits among 14729 adults. Thorax 1988; 43: 534-539.

23. Oryszczyn MP, Annesi I, Neukirch F, Dore MF, Kauffmann F. Relationships of total IgE level, skin prick test response, and smoking habits. Ann Allergy 1991; 67: 355-358.

24. Kauffmann F, Annesi I, Enarson DA. Tobacco smoke and bronchial responsiveness. In: Hirsch A, Goldberg M, Martin JP, Masse R, Eds. Prevention of Respiratory Diseases. New York, Marcel Dekker, 1993; pp. 463-496.

25. Kaplan BA, Mascie-Taylor CGN. Smoking and asthma among 23-year-olds. J Asthma 1997; 34: 219-226.

26. Ulrik C, Frederiksen J. Mortality and markers of risk of asthma death among 1075 outpatients with asthma. Chest 1995; 108: 10-15.

27. Ryan G, Stock H, Musk AW, Knight JL, Perera DM, Hobbs MST. Risk factors for death in patients admitted to hospital with asthma: a follow-up study. Aust $N Z \mathrm{~J} \mathrm{Med}$ 1991; 21: 681-685.

28. LeSon S, Gershwin ME. Risk factors for asthmatic patients requiring intubation. III. Observations in young adults. J Asthma 1996; 33: 27-35.

29. Hanania NA, David-Wang A, Kesten S, Chapman KR. Factors associated with emergency department dependence of patients with asthma. Chest 1997; 111: 290-295.

30. Turner MO, Noertjojo K, Vedal S, Bai T, Crump S, Fitzgerald JM. Risk factors for near-fatal asthma. A casecontrol study in hospitalized patients with asthma. Am J Respir Crit Care Med 1998; 157: 1804-1809.

31. Marquette $\mathrm{CH}$, Saulnier F, Leroy O, et al. Long-term prognosis of near-fatal asthma. A 6-year follow-up study of 145 asthmatic patients who underwent mechanical ventilation for a near-fatal attack of asthma. Am Rev Respir Dis 1992; 146: 75-81.

32. Hong CY, Ng TP, Wong ML, Koh KTC, Goh LG, Ling SL. Lifestyle and behavioural risk factors associated with asthma morbidity in adults. $Q J$ Med 1994; 87: 639-645.

33. Prescott E, Lange P, Vestbo J, and the Copenhagen city Heart study group. Effect of gender on hospital admissions for asthma and prevalence of self reported asthma: a prospective study based on a sample of the general population. Thorax 1997; 52: 287-289.

34. Murray AB, Morrison BJ. The decrease in severity of asthma in children of parents who smoke since the parents have been exposing them to less cigarette smoke. $J$ Allergy Clin Immunol 1993; 91: 102-110.

35. Bucknall CE, Robertson C, Moran F, Stevenson RD. Differences in hospital asthma management. Lancet 1988; i: $748-750$. 